\title{
Lattice location and thermal stability of implanted Fe in ZnO
}

\author{
E. Rita ${ }^{\text {a) b) }}$, U. Wahl, J.G. Correia ${ }^{\text {b) }}$, E. Alves \\ Instituto Tecnológico e Nuclear, Estrada Nacional 10, 2686-953 Sacavém, Portugal, and \\ Centro de Física Nuclear da Universidade de Lisboa, Avenida Professor Gama Pinto 2, 1649-003 Lisboa, Portugal \\ J.C. Soares \\ Centro de Física Nuclear da Universidade de Lisboa, Avenida Professor Gama Pinto 2, 1649-003 Lisboa, Portugal
}

The ISOLDE collaboration

CERN-PH, 1211 Geneva 23, Switzerland

(Received 16 August 2004; accepted 23 September 2004)

The emission channeling technique was applied to evaluate the lattice location of implanted ${ }^{59} \mathrm{Fe}$ in singlecrystalline $\mathrm{ZnO}$. The angular distribution of $\beta^{-}$particles emitted by ${ }^{59} \mathrm{Fe}$ was monitored with a position-sensitive electron detector, following $60-\mathrm{keV}$ low dose $\left(2.0 \times 10^{13} \mathrm{~cm}^{-2}\right)$ room-temperature implantation of the precursor isotope ${ }^{59} \mathrm{Mn}$. The emission patterns around the [0001], [1102], [1101] and [2113] directions revealed that following annealing at $800^{\circ} \mathrm{C} 95(8) \%$ of the $\mathrm{Fe}$ atoms occupy ideal substitutional $\mathrm{Zn}$ sites with root mean square displacements of 0.06-0.09 ̊. @ 2004 American Institute of Physics.

Numerous technological breakthroughs are envisaged with the use of magnetic semiconductor materials that show a ferromagnetic ordering temperature at or above room temperature, e.g., spin transistors, ultradense nonvolatile memories and optical emitters with polarized output [1]. One class of materials, which are especially promising for applications, are diluted magnetic semiconductors, usually ternary systems of the type $\mathrm{III}_{1-\mathrm{x}}-\mathrm{TM}_{\mathrm{x}}-\mathrm{V}$ or $\mathrm{II}_{1-}$ ${ }_{\mathrm{x}}-\mathrm{TM}_{\mathrm{x}}-\mathrm{VI}$, where a $3 d$ transition metal (TM) partly substitutes up to a few per cent of the group III or group II cations. It has been predicted by theory that the III-nitride semiconductors GaN and InN and the II-oxide semiconductor $\mathrm{ZnO}$ are suitable hosts to exhibit ferromagnetism close to or above room temperature [2,3]. In the case of $\mathrm{ZnO}$, besides V, Cr, Mn, Co and Ni, Fe should also act as a ferromagnetic dopant [3-5]. Several reports on ferromagnetic systems based on $\mathrm{ZnO}$ can be found in the literature [1,614]. Cases in which no ferromagnetic behavior was observed [7, 15-18] revealed systematic trends for the various transition metals, doping concentrations, and differences between $n$ - and $p$-type $\mathrm{ZnO}$, but also conflicting results between different authors. It was thus argued [11,14] that experimental reproducibility needs to be improved. The exact nature of the ferromagnetism also remains unclear $[1,8,11,13]$; among possible problems are the formation of metallic TM or TM-oxide clusters [9,12-14,17] or magnetism from the substrate on which thin films are deposited [18]. Two recent review papers on the subject concluded that a more precise control of the TM dopant in the oxide and careful structural and microstructural analyses are needed $[1,11]$.

Experimentally TM dopants have been introduced both during $\mathrm{ZnO}$ powder synthesis $[10,14,16]$ and growth of epitaxial thin films $[6-9,11,15,18]$. In addition, ion implantation is also actively being explored for TM doping of $\mathrm{ZnO}[1,12,13,19]$. With respect to implantation, the questions that should be clarified, are: to what extent are TMs incorporated into the proper lattice sites (substituting for $\mathrm{Zn}$ atoms), what is the microstructure of substitutional TMs, and what are the optimum annealing conditions.

We have partly addressed some of these issues in a previous study on Fe-implanted $\mathrm{ZnO}$ [20], which, however, focused on its optical properties. In that case, ${ }^{56} \mathrm{Fe}$ was implanted at $100 \mathrm{keV}$ up to a fluence of $10^{16} \mathrm{~cm}^{-2}$ into $\mathrm{ZnO}$ single crystals, followed by Rutherford backscattering spectroscopy (RBS) analysis of the damage and its recovery during thermal annealing. Since $\mathrm{Fe}$ in $\mathrm{ZnO}$ cannot be detected by RBS, particle-induced X-ray emission (PIXE) had to be used as the probing reaction, giving only limited results on the Fe lattice location. It was found that in the asimplanted state around $56 \%$ of $\mathrm{Fe}$ atoms were aligned with the $\mathrm{ZnO} c$-axis, increasing to around $73 \%$ following annealing in air at $1050^{\circ} \mathrm{C}$.

In this work, we have examined in detail the lattice location of radioactive ${ }^{59} \mathrm{Fe}\left(t_{1 / 2}=44.6 \mathrm{~d}\right)$ in single-crystalline $\mathrm{ZnO}$ by means of the emission channeling technique [21]. Using a position-sensitive electron detector [22] the angular distribution of $\beta^{-}$particles emitted by ${ }^{59} \mathrm{Fe}$ was measured and provided information about the emitter lattice site. A commercially available $\mathrm{ZnO}$ [0001] single crystal [23], grown by seeded chemical vapor transport and polished on the $\mathrm{Zn}$ face, was implanted at room temperature with the precursor isotope ${ }^{59} \mathrm{Mn}\left(t_{1 / 2}=4.6 \mathrm{~s}\right)$ at $60 \mathrm{keV}$ energy up to a dose of $2.0 \times 10^{13} \mathrm{~cm}^{-2}$. The implantation was performed at the CERN/ISOLDE facility [24]. A $7^{\circ}$ angle from the surface normal was applied in order to minimize the fraction of ${ }^{59} \mathrm{Mn}$ atoms channeled during implantation and provide a well-defined depth profile (range $299 \AA$ and straggling $136 \AA$ ).

It is important to point out that the ${ }^{59} \mathrm{Mn} \beta^{-}$decay transfers $200 \mathrm{eV}$ of recoil energy to its daughter ${ }^{59} \mathrm{Fe}$. This energy is sufficiently high to re-implant the Fe atoms, assuring in this way that they will not inherit the ${ }^{59} \mathrm{Mn}$ lattice site. After the implantation, the $\beta^{-}$emission channeling 


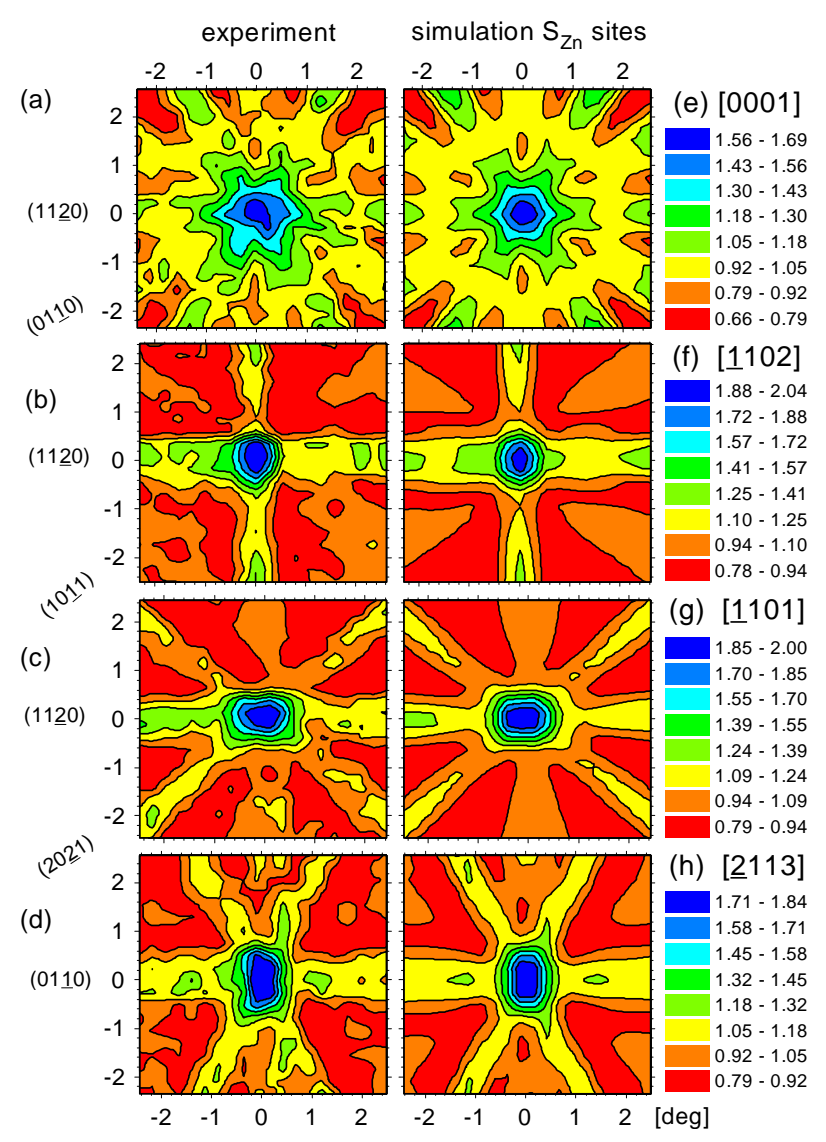

FIG. 1. Angular distribution of $\beta^{-}$particle emission yields from ${ }^{59} \mathrm{Fe}$ in $\mathrm{ZnO}$, around the [0001] (a), [1102] (b), [1101] (c) and [2113] (d) axes, following $800^{\circ} \mathrm{C}$ annealing. The best fits of the channeling patterns for each direction are also shown and correspond to $95(8) \%$ of $\mathrm{Fe}$ atoms at $\mathrm{S}_{\mathrm{Zn}}$ sites.

patterns from ${ }^{59} \mathrm{Fe}$ were recorded around the [0001], [1102], [1101] and [2113] directions by means of a position-sensitive detector, providing unambiguous information about the emitter lattice site. These measurements were carried out in the as-implanted state, following $10 \mathrm{~min}$ in situ vacuum annealing steps at $300^{\circ} \mathrm{C}, 600^{\circ} \mathrm{C}, 800^{\circ} \mathrm{C}$, and $900^{\circ} \mathrm{C}$ and an additional annealing step under air at $1050^{\circ} \mathrm{C}$ for $30 \mathrm{~min}$.

The subsequent evaluation of the Fe lattice location was performed by quantitatively comparing the experimental patterns with theoretical ones, using the twodimensional fitting procedure outlined in Ref. [22]. In this procedure, theoretical patterns for ${ }^{59} \mathrm{Fe}$ at substitutional $\mathrm{Zn}$ sites $\left(\mathrm{S}_{\mathrm{Zn}}\right)$ and $\mathrm{O}$ sites $\left(\mathrm{S}_{\mathrm{O}}\right)$ with varying root mean square (rms) displacements and a diversity of interstitial sites were considered [25]. The ${ }^{59} \mathrm{Fe}$ theoretical emission channeling patterns were calculated by means of the "manybeam" theory of electron diffraction in single-crystals [21]. The computational approach for $\beta^{-}$emitters in $\mathrm{ZnO}$ has been described previously [26].

The experimental emission patterns along the [0001], [1102], [1101] and [2113] directions, following $800^{\circ} \mathrm{C}$ annealing, are shown in Figure 1(a)-(d). Figure 1 (e)-(h) represent the best two-fraction fits of the corresponding theoretical yields, obtained by considering only Fe on substitu-

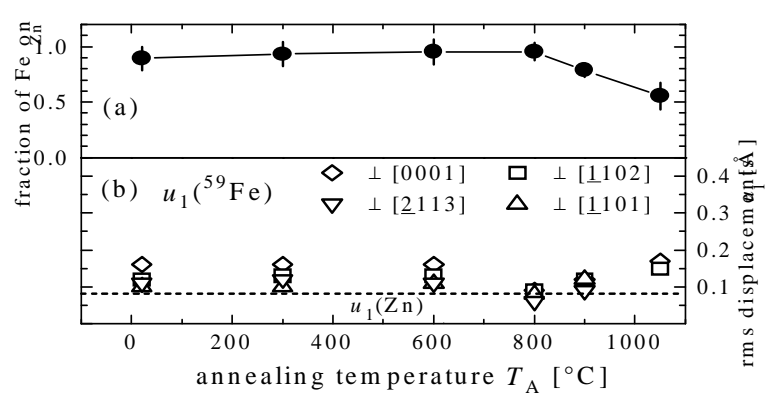

FIG. 2. Fraction of Fe atoms on substitutional $\mathrm{Zn}$ sites (a) and their room temperature rms displacements perpendicular to the [0001], [1102], [1101] and [2113] crystal directions (b) following annealing steps $\left(10 \mathrm{~min}\right.$ in vacuum up to $900^{\circ} \mathrm{C}, 30 \mathrm{~min}$ in air at $1050^{\circ} \mathrm{C}$ ). The dotted line indicates the room temperature rms displacements of $\mathrm{Zn}$ atoms.

tional $\mathrm{S}_{\mathrm{Zn}}$ sites and varying its rms displacement $u_{1}(\mathrm{Fe})$, and $\mathrm{Fe}$ on random sites. Note that the latter fraction accounts for sites contributing with an isotropic emission yield, which are sites of very low crystal symmetry or in heavily damaged surroundings. For this annealing temperature, the ${ }^{59} \mathrm{Fe}$ rms displacements from $\mathrm{S}_{\mathrm{Zn}}$ sites which gave the best fit were $0.09 \AA, 0.09 \AA, 0.08 \AA$ and $0.06 \AA$, perpendicular to the [0001], [1102], [1101] and [2113] directions, respectively, and the corresponding fractions on $\mathrm{S}_{\mathrm{Zn}}$ sites were $108 \%, 93 \%, 93 \%$ and $88 \%$.

Figure 2 shows the substitutional $\mathrm{Fe}$ fractions and rms displacements as a function of annealing temperature. As can be seen, almost $90 \%$ of Fe atoms were found on substitutional $\mathrm{Zn}$ sites already in the as-implanted state, but with rms displacements from ideal $\mathrm{Zn}$ positions of around $0.10-0.16 \AA$. Annealing up to $600^{\circ} \mathrm{C}$ practically did not change this situation, while the $800^{\circ} \mathrm{C}$ anneal induced a significant decrease of the Fe rms displacements. On the other hand, the annealing steps at $900^{\circ} \mathrm{C}$ and $1050^{\circ} \mathrm{C}$, caused not only a decrease of the ${ }^{59} \mathrm{Fe}$ fraction on $\mathrm{S}_{\mathrm{Zn}}$ sites to $79 \%$ and $55 \%$, respectively, but also an increase of the Fe rms displacements. Apart from the small random fractions we found no evidence for ${ }^{59} \mathrm{Fe}$ located at other lattice sites than $\mathrm{S}_{\mathrm{Zn}}$.

The most remarkable feature of our experimental results is the almost perfect substitutional incorporation of $\mathrm{Fe}$ at $\mathrm{Zn}$ sites found after the $800^{\circ} \mathrm{C}$ annealing. The observed rms displacement values are close to the thermal vibration amplitude of the $\mathrm{Zn}$ atoms, $u_{1}(\mathrm{Zn})=0.082 \AA$, and represent the lowest rms displacements we have found so far for any impurity in $\mathrm{ZnO}$. The somewhat higher rms values observed in the as-implanted state are ascribed to the damage in the surroundings of $\mathrm{Fe}$ introduced by the implantation, which is then largely removed during annealing at $800^{\circ} \mathrm{C}$. The fact that the substitutional $\mathrm{Fe}$ fraction decreases again for higher annealing temperatures, accompanied by a small increase in the Fe rms displacements, may be explained as follows. High temperature annealing is likely to introduce crystal defects in the near-surface layers, which can interact with $\mathrm{Fe}$ atoms, causing them to occupy lattice locations of lower symmetry. This process is possibly further enhanced by Fe diffusion at these temperatures, 
which would also allow for the possible formation of $\mathrm{Fe}$ clusters.

In previous emission channeling experiments we investigated the lattice location of the transition metal isotopes ${ }^{67} \mathrm{Cu}$ [26] and ${ }^{111} \mathrm{Ag}$ [27] implanted in $\mathrm{ZnO}$ and found quite different results in terms of thermal stability of the dopant lattice site. Despite of the majority $(60 \%)$ of ${ }^{67} \mathrm{Cu}$ atoms being substitutional at $\mathrm{S}_{\mathrm{Zn}}$ sites already in the as-implanted state with low rms displacements (0.16$0.17 \AA$ ), annealing above $400^{\circ} \mathrm{C}$ caused a dramatic increase in the ${ }^{67} \mathrm{Cu}$ rms displacements $(0.3-0.5 \AA)$ from $\mathrm{S}_{\mathrm{Zn}}$ sites, along with the partial outdiffusion of $\mathrm{Cu}$ during the $800^{\circ} \mathrm{C}$ annealing. The case of $\mathrm{Ag}$ was very similar to $\mathrm{Cu}$, however, with maximum substitutional fractions around $40 \%$ only. In contrast, the comparably high stability of $\mathrm{Fe}$ against annealing is underlining the potential of ion implantation as a means of Fe doping in $\mathrm{ZnO}$.

We should point out that the ${ }^{59} \mathrm{Fe}$ peak concentration in our experiment was $5.6 \times 10^{18} \mathrm{~cm}^{-3}$ or $67 \mathrm{ppm}$, which is considerably lower than usually applied for diluted magnetic semiconductors. For instance, implants for producing $\mathrm{ZnO}$ diluted magnetic semiconductors were done with $250 \mathrm{keV}{ }^{55} \mathrm{Mn}$ or ${ }^{59} \mathrm{Co}$ up to fluences of $3-5 \times 10^{16} \mathrm{~cm}^{-2}$, leading to concentration maxima around $3-5 \%$ [Norton 03 , Theodoropoulou 03]. In future studies we will therefore also explore the ${ }^{59} \mathrm{Fe}$ lattice location in samples coimplanted with high doses of stable ${ }^{56} \mathrm{Fe}$.

In conclusion, we have demonstrated that for implantation at low doses almost all Fe atoms, 95(8)\%, can be incorporated on ideal substitutional $\mathrm{Zn}$ sites with low rms displacements $(0.06-0.09 \AA)$. There were no evidences for $\mathrm{Fe}$ in other regular lattice locations. While the substitutional incorporation occurs already in the as-implanted state, annealing in vacuum at $800^{\circ} \mathrm{C}$ is required to promote substitutional $\mathrm{Fe}$ with rms displacements similar to the thermal vibration amplitude of $\mathrm{Zn}$ atoms. Annealing at higher temperatures, up to $1050^{\circ} \mathrm{C}$, resulted in a decrease of the substitutional $\mathrm{Fe}$ fraction and a small increase of its rms displacements. However, in comparison to $\mathrm{Cu}$ and $\mathrm{Ag}$ the Fe lattice site in $\mathrm{ZnO}$ proved to be relatively stable at high temperatures.

This work was funded by the FCT, Portugal (project POCTI-FNU-49503-2002) and by the European Union (Large Scale Facility contract HPRI-CT-1999-00018). E. Rita and U. Wahl, acknowledge their fellowships supported by the FCT, Portugal.

a) corresponding author, email elisabete.rita@ cern.ch
b) on leave at CERN-PH, 1211 Geneva 23, Switzerland

[1] S.J. Pearton, C.R. Abernathy, M.E. Overberg, G.T. Thaler, D.P. Norton, N. Theodoropoulou, A.F. Hebard, Y.D. Park, F. Ren, J. Kim, and L.A. Boatner, J. Appl. Phys. 93, 1 (2003).

[2] T. Dietl, H. Ohno, F. Matsukura, J. Cibert, and D. Ferrand, Science 287, 1019 (2000).

[3] K. Sato and H. Katayama-Yoshida, Semicond. Sci. Technol. 17, 367 (2002).

[4] K. Sato and H. Katayama-Yoshida, Jpn. J. Appl. Phys. Part 2 39, L555 (2000).
[5] M.S. Park and B.I. Min, Phys. Rev. B 68, 224436 (2003).

[6] K. Ando, H. Saito, Z. Jin, T. Fukumura, M. Kawasaki, Y. Matsumoto, and H. Koinuma, J. Appl. Phys. 89, 7284 (2001).

[7] Z. Jin, T. Fukumura, M. Kawasaki, K. Ando, H. Saito, T. Sekiguchi, Y.Z. Yoo, M. Murakami, Y. Matsumoto, T. Hasegawa, and H. Koinuma, Appl. Phys. Lett. 78, 3824 (2001).

[8] K. Ueda, H. Tabata, and T. Kawai, Appl. Phys. Lett. 79, 988 (2991).

[9] H. Tabata, M. Saeki, S.L. Guo, J.H. Choi, and T. Kawai, Physica B 308, 993 (2001).

[10] S.J. Han, J.W. Song, C.H. Yang, S.H. Park, J.H. Park, Y.H. Yeong, and K.W. Rhie, Appl. Phys. Lett. 81, 4212 (2002).

[11] W. Prellier, A. Fouchet, and B. Mercey, J. Phys: Condens. Matter 15, R1583 (2003).

[12] D.P. Norton, S.J. Pearton, A.F. Hebard, N. Theodoropoulou, L.A. Boatner, and R.G. Wilson, Appl. Phys. Lett. 82, 239 (2003).

[13] N. Theodoropoulou, A.F. Hebard, D.P. Norton, J.D. Budai, L.A. Boatner, J.S. Lee, Z.G. Khim, Y.D. Park, M.E. Overberg, S.J. Pearton, and R.G. Wilson, Solid State Electronics 47, 2231 (2003).

[14] Y.H. Jeong, S.J. Han, J.H. Park, and Y.H. Lee, J. Magn Magn. Mater. 272, 1976 (2004).

[15] T. Fukumura, Z. Jin, M. Kawasaki, T. Shono, T. Hasegawa, S. Koshihara, amd H. Koinuma, Appl. Phys. Lett. 78, 958 (2001).

[16] S.W. Yoon, S.B. Cho, S.C. We, S. Yoon, B.J. Suh, H.K. Song, and Y.J. Shin, J. Appl. Phys. 93, 7879 (2003).

[17] S. Kolesnik, B. Dabrowski, and J. Mais, J. Appl. Phys. 95, 2582 (2994).

[18] E. Guzmán, H. Hochmuth, M. Lorenz, H. von Wenckstern, A. Rahm, E.M. Kaidashev, M. Ziese, A. Setzer, P. Esquinazi, A. Pöppl, D. Spemann, R. Pickenhain, H. Schmidt, and M. Grundmann, Ann. Phys. 13, 57 (2004).

[19] S.J. Pearton, C.R. Abernathy, G.T. Thaler, R. Frazier, F. Ren, A.F. Hebard, Y.D. Park, D.P. Norton, W. Tang, M. Stavola, J.M. Zavada and R.G. Wilson, Physica B 340, 39 (2003).

[20] T. Monteiro, C. Boemare, M.J. Soares, E. Rita, and E. Alves, J. Appl. Phys. 93, 8995 (2003).

[21] H. Hofsäss and G. Lindner, Phys. Rep. 210, 121 (1991).

[22] U. Wahl, J.G. Correia, A. Czermak, S.G. Jahn, P. Jalocha, J.G. Marques, A. Rudge, F. Schopper, A. Vantomme, P. Weilhammer, and the ISOLDE collaboration, Nucl. Instr. Meth. A 524 (2004) 245.

[23] Eagle-Picher Technologies, Miami, OK 74354.

[24] E. Kugler, D. Fiander, B. Jonson, H. Haas, A. Przewloka, H.L. Ravn, D.J. Simon, K. Zimmer, and the ISOLDE collaboration, Nucl. Instrum. Meth. B 70, 41 (1992).

[25] U. Wahl, A. Vantomme, G. Langouche, J.P. Araújo, J.G. Correia, L. Peralta, and the ISOLDE collaboration, J. Appl. Phys. 88, 1319 (2000).

[26] U. Wahl, E. Rita, J.G. Correia, E. Alves, J.C. Soares and the ISOLDE collaboration, Phys. Rev. B 69, 012102 (2004).

[27] E. Rita, U. Wahl, A.M.L. Lopes, J.P. Araújo, J.G. Correia, E. Alves, J.C. Soares and the ISOLDE collaboration, Physica B 340, 240 (2003). 